\title{
Postural Control Modulation During Motor Imagery Tasks: A Systematic Review

\begin{abstract}
Nélio Silva de Souza1, Ana Carolina Gomes Martins², Keila da Silva Canuto ${ }^{3}$, Dionis Machado4, Silmar Teixeira 4,6,7, Marco Orsini ${ }^{5}$, Manuel Menendez-Gonzalez ${ }^{9}$, Bruna Velasques 7,8, Pedro Ribeiro7,8, Victor Hugo do Vale Bastos4,6, Oscar Arias-Carrión 10,11*
\end{abstract}

\section{Abstract}

The motor imagery (MI) has two strategies (kinesthetic and visual) and can be defined as an act to codify the mental rehearsal of an intended action, without executing it. Studying the execution of the movement, several researchers believe that the deep muscles of the trunk are activated before the agonist of the limbs, showing a motor neurophysiologic recruitment order. This behavior can be also seen during $\mathrm{Ml}$ tasks as the postural control, because the postural control is inserted in the movement context. The aim was to investigate, by a systematic review, evidences of $\mathrm{Ml}$ and the postural control on healthy subjects. The selected articles were searched on different databases, dated from 1985 to 2014. Twelve studies were selected regarding the $\mathrm{MI}$ and the postural control on healthy subjects. All articles using balance scale or those which were about clinical conditions were excluded. Data show that kinesthetic Ml with high levels of vividness promotes major changes in the body oscillations when comparing with the visual MI. To date, the number of articles about this theme is limited and the results should be interpreted cautiously.

\section{Keywords}

Postural control; postural balance; motor imagery; mental simulation; mental training
1 Augusto Motta University Center (UNISUAM), Rio de Janeiro, Brazil.

2 Fluminense Federal University (UFF), Niterói, Brazil.

3 Serra dos Órgãos University Center, (UNEFESO), Teresópolis, Brazil

4 Brain Mapping and Plasticity Laboratory, Federal University of Piauí (LAMPLACE/ UFPI), Parnaíba, Brazil.

5 Antônio Pedro University Hospital, Niterói, Rio de Janeiro, Brazil.

6 Brain Mapping and Functionality Laboratory, Federal University of Piauí (LAMCEF/UFPI), Parnaíba, Brazil.

7 Brain Mapping and Sensory Motor Integration, Institute of Psychiatry of Federal University of Rio de Janeiro (IPUB/ UFRJ), Brazil.

8 Institute of Applied Neuroscience (INA), Rio de Janeiro, Brazil.

9 Unidad de Neurología, Hospital ÁlvarezBuylla Mieres, Spain ; Departamento de Morfología y Biología Celular, Universidad de Oviedo Oviedo, Spain ; Instituto de Neurociencias, Universidad de Oviedo Oviedo, Spain.

10 Unidad de Trastornos del Movimiento y Sueño (TMS), Hospital General Dr. Manuel Gea González/IFC-UNAM, México D.F., México.

11 Unidad de Trastornos del Movimiento y Sueño (TMS), Hospital General Ajusco Medio, Secretaría de Salud, México D.F., México

Contact information:

\section{Introduction}

The motor imagery (MI) can be defined as the act to codify the mental rehearsal of an intended action, without executing it [1]. The MI has two strategies: (1) kinesthetic (first person), which the individual feels himself executing the movement and (2) visual (third
” arias@ciencias.unam.mx 
person), which the individual sees the movement performed by himself or another person [2]. The imagination and the feeling of a movement are phenomenona specifically related, and they have a voluntary control profile [3]. This conscious action can bring non conscious neurophysiologic changes and also induce events through the autonomic nervous system (ANS) [4]. Different methodologies have shown the relevance of $\mathrm{Ml}$ through human body. These findings reassure that there are common neural mechanisms between $\mathrm{Ml}$ and the movement execution (ME) [5], that can modify the electroencephalographic (EEG) signal during the mental effort tasks [6], and also induce changes on cardio-respiratory activities in the same conditions [7-12].

Several studies in neuroscience have evidenced the benefits of $\mathrm{Ml}$ and propose their use in improving performance or functional recovery in different conditions: sports practice [13-14]; geriatric [15]; amputation [16]; gait disorder [17-20]; neurological disorder [21-25] and orthopedic disorder, including the postural control [26-28]. The postural control system depends on three functional components: (1) biomechanics, involving muscular and join extensibility, as well as the range of motion of each body segment; (2) motor skills, which involves the strategies of response to the anteroposterior body sway (ankle and knee strategy) and external interferences (hip strategy) [29-32] and (3) sensorial system (visual, vestibular and proprioceptive), responsible for the control of postural balance [33-34].

Traditionally, it was believed that only the basal ganglia, cerebellum and spinal cord regulated the postural control [35] and historically, that this type of control was basically an automated sensoriomotor task [30, 36-37]. However, it was observed that both animals and humans with cortical injury (with cerebellum and brainstem preserved) showed an abnormal postural control [38], supporting the hypothesis that the cerebral cortex could interfere in the adjustment of postural balance in voluntary res- ponses [39]. Furthermore, the motor system is involved not only in producing the movement, but also in its representational aspects, such as recognition and action learning through observation and mental simulation [40]. Part of the neuronal mechanisms involved in the movement planning is also recruited during the mental simulation state designated as "S-state". Those "S-states" are related to situation which anticipates the action, manipulating neuronal networks that codify the intended action, without the execution [4-5].

In this context, the voluntary movement could be linked to the postural control. Therefore, it could be expected that the simulation of a movement during a $\mathrm{Ml}$ task could activate part of the circuit and induce a postural adjustment. Investigations involving the $\mathrm{MI}$ and postural control are very recent [41-49] and have been speculated that the MI blocks the ME in different brain levels, although those mechanisms are yet not well understood (for review see references [5] and [40]). The objective of this study was to investigate, through a systematic review, the evidence of correlation between the $\mathrm{Ml}$ and the postural control in healthy subjects.

\section{Methodos}

The present study is characterized by a systematic literature review, which aims to gather, critically evaluate and conduct a synthesis of scientific evidence [50].

\subsection{Data's source}

On this systematic review, two books were used, one about the "Global Postural Reprogramming" [35] and the other about "The Neurophysiological Foundations of Mental and Motor Imagery" [4]. Those books are extremely relevant to this specific area of knowledge. For this specific subject, articles published on the following databases were selected: Pub med/Medline; Scholar Google; PEDro and Scielo, using motor imagery, postural control and 
mental training combined or not either in English as key-words, the articles are dated from 1985 to 2014 (see table 1). They were used on the theoretical substantiation and discussion different articles in a larger period (1910 - 2014), which the more parcel of information were from the past 10 years. 49 references were referent to the last 10 years (20052015) and all the others (51 references) have more than 10 years or more of publication $(\leq 2005)$.

\subsection{Types of study}

Studies about the randomized and controlled clinical rehearsal, as well as the observational studies of the transversal type were selected. They explore the evidences on the correlation between the MI (or mental training) over the balance control in healthy people using the force platform as an instrument to quantify the Center of Pressure (CoP).

\subsection{Participants, intervention and exclusion criteria}

Studies that analyzed healthy people with no neurologic and/or orthopedic injuries which could implicate the balance were included. In these studies, the Ml or mental practice should be accomplished and also analyze the postural balance control through force platform, since this is a reproductive method [51], reliable [52-54] and validated [55]. 24 references were eliminated that used only the scale to measure the balance or mentioned clinical conditions (Stroke and Parkinson disease). On all articles about the subject, only one used oscilloscope to evaluate balance control [26], the remnant of the articles used force platform on healthy subject.

\section{Results}

In total, twelve references were selected about the MI and the postural control, from 1985 to 2014. In the table 1 summarizes the results of the articles research at the databases, and also the articles level of evidence of the articles and its impact factor in each journal. Table 2 summarizes the studies about the randomized and controlled clinical rehearsal; finally, table 3 referrers to the observational studies from the transversal type.

Table 1. Research results at the databases.

\begin{tabular}{|c|c|c|c|c|c|}
\hline Database & $\begin{array}{l}\text { Articles } \\
\text { Found }\end{array}$ & Selected & Author and Year & Level of evidence & $\begin{array}{l}\text { Journal's impact } \\
\text { factor in } 2013\end{array}$ \\
\hline \multirow{7}{*}{$\begin{array}{l}\text { Pub med/ } \\
\text { Medline }\end{array}$} & \multirow[t]{7}{*}{24} & \multirow[t]{7}{*}{7} & Imbiriba et al., 2006 [43] & & \\
\hline & & & Rodrigues et al., 2010 [41] & & 2.026 \\
\hline & & & Grangeon, Guillot \& Collet, 2011 [44] & & 3.122 \\
\hline & & & Heurley et al., 2013 [46] & & 1.536 \\
\hline & & & Kawasaki \& Higuchi, 2013 [47] & & 1.393 \\
\hline & & & Boulton \& Mitra, 2013 [45] & & 1.060 \\
\hline & & & Lemos, Rodrigues \& Vargas, 2014 [49] & & 3.301 \\
\hline \multirow[t]{2}{*}{ PEDro } & \multirow[t]{2}{*}{8} & \multirow[t]{2}{*}{2} & Hamel \& Lajoie, 2005 [28] & $2 / 10$ & 1.006 \\
\hline & & & Fansler, Poff \& Shepard, 1985 [26] & $5 / 10$ & 3.360 \\
\hline SciELO & 1 & 1 & Rodrigues et al., 2003 [42] & & 1.856 \\
\hline \multirow{2}{*}{$\begin{array}{l}\text { Scholar } \\
\text { Google }\end{array}$} & \multirow[t]{2}{*}{3} & \multirow[t]{2}{*}{2} & Choi et al., 2010 [27] & & 0.180 \\
\hline & & & Lemos et al., 2014 [48] & & 2.906 \\
\hline
\end{tabular}


Table 2. Studies trial clinical randomized and controlled.

\begin{tabular}{|c|c|c|c|c|}
\hline $\begin{array}{l}\text { Author and } \\
\text { Year }\end{array}$ & Sample & Intervention & Methodology & Results and Conclusions \\
\hline $\begin{array}{l}\text { Fansler, Poff } \\
\text { \& Shepard, } \\
(1985)[26]\end{array}$ & $\begin{array}{l}n=36 \text { (women over } 70 \\
\text { years), } \\
n=12 \text { for each group }\end{array}$ & $\begin{array}{l}\text { Group A: attention and } \\
\text { participation tasks } \\
\text { Group B: relaxing instructions } \\
\text { Group C: MP and physical } \\
\text { practice the balance control in } \\
\text { one leg } 3 \text { groups realized the } \\
\text { tasks for } 3 \text { following days }\end{array}$ & Oscilloscope & $\begin{array}{l}\text { The MP associated with physical } \\
\text { practice can improve the } \\
\text { balance control in one leg }\end{array}$ \\
\hline $\begin{array}{l}\text { Hamel } \\
\text { \& Lajoie, } \\
\text { (2005) [28] }\end{array}$ & $\begin{array}{c}\mathrm{n}=20 \text { (aged } 65 \text { to } 90 \\
\text { years old) } \\
\mathrm{n}=12 \text { (experimental } \\
\text { group) } \\
\mathrm{n}=8 \text { (control group) }\end{array}$ & $\begin{array}{l}\text { Experimental group: After listen } \\
\text { signal, the participants should } \\
\text { performed the MP maintaining } \\
\text { a straight and stable standing } \\
\text { position once a day (dual-task), } \\
\text { in six consecutive weeks. } \\
\text { Control group: Did not receive } \\
\text { any MP training Both groups } \\
\text { performed five minutes of } \\
\text { relaxation }\end{array}$ & $\begin{array}{l}\text { Force platform } \\
(50 \mathrm{~Hz}), \text { Berg } \\
\text { balance scale } \\
\text { and KMI e VMI } \\
\text { survey (KVIQ) }\end{array}$ & $\begin{array}{l}\text { The PM showed significantly } \\
\text { reduced the reaction time } \\
\text { demand attention in dual- } \\
\text { task and the oscillation in the } \\
\text { AP directions of CoP when } \\
\text { compared with the control } \\
\text { group }\end{array}$ \\
\hline $\begin{array}{l}\text { Choi et al., } \\
(2010)[27]\end{array}$ & $\begin{array}{l}\mathrm{n}=21 \text { ( } 7 \text { men and } 14 \\
\text { women healthy, } \\
\text { aged to } 20 \text { years } \\
\text { old), } \\
\mathrm{n}=7 \text { for each group }\end{array}$ & $\begin{array}{l}\text { Physical Practice (PP) Group*: } \\
\text { Received the balance treatment } \\
\text { together to the visual feedback } \\
\text { of the CoP } \\
\text { MP Group*: performed the MP } \\
\text { of the same training received } \\
\text { at FP } \\
\text { * Both groups accomplished } 30 \\
\text { minutes of MP, in } 5 \text { days for } 3 \\
\text { consecutive weeks } \\
\text { Control Group (CG): This group } \\
\text { did not accomplish any kind of } \\
\text { training }\end{array}$ & $\begin{array}{l}\text { Force platform } \\
(50 \mathrm{H}) \text { and } \\
\text { feedback } \\
\text { visual training } \\
\text { equipment }\end{array}$ & $\begin{array}{l}\text { The FP group showed } \\
\text { improvement compared with } \\
\text { MP and CG. The PM group } \\
\text { showed an improvement when } \\
\text { compared with the CG. The } \\
\text { authors concluded that the MP } \\
\text { in postural balance disorders } \\
\text { can be effective }\end{array}$ \\
\hline Legend: $s=$ & nds; $\mathrm{Ml}=$ motor $\mathrm{imac}$ & $\mathrm{KMI}=$ kinesthetic motor imag & ; VMI= visual mc & $\begin{array}{l}\text { otor imagery; } \\
\text {; CoG= center of gravity; }\end{array}$ \\
\hline
\end{tabular}

Table 3. Observational studies of the transversal type.

\begin{tabular}{|c|c|c|c|c|}
\hline $\begin{array}{c}\text { Author and } \\
\text { Year }\end{array}$ & Sample & Intervention & Methodology & Results / conclusions \\
\hline $\begin{array}{l}\text { Rodrigues } \\
\text { et al., (2003) } \\
{[42]}\end{array}$ & $\begin{array}{c}\mathrm{n}=49 \text { (23 male sand } 26 \\
\text { females healthy } \\
\text { with aged to } 23 \\
\text { years old) }\end{array}$ & $\begin{array}{l}\text { Tasks: } \\
\text { a) remain standing during } 20 \text {; } \\
\text { b) count mentally from } 1 \text { to } 15 \text {; } \\
\text { c) imagine themselves executing } \\
\text { a rising on tiptoes } 15 \text { times and } \\
\text { d) execute the same movement } \\
15 \text { times. } \\
\text { The groups were separated } \\
\text { according to the strategy } \\
\text { adopted (VMI or KMI) }\end{array}$ & $\begin{array}{l}\text { Mental } \\
\text { chronometry } \\
\text { and force } \\
\text { platform } \\
(50 \mathrm{~Hz}) \text {. The } \\
\text { EMGS register } \\
\text { was not carried } \\
\text { out }\end{array}$ & $\begin{array}{l}\text { The mental chronometry did } \\
\text { not show any difference. } \\
\text { A significant increase in the } \\
\text { displacement of the CoP in the } \\
\text { AP direction in participants } \\
\text { found made use of kinesthetic } \\
\text { strategy, with no significant } \\
\text { changes in the oscillations of } \\
\text { the CoP in the group using the } \\
\text { visual strategy }\end{array}$ \\
\hline
\end{tabular}




\begin{tabular}{l|c}
$\begin{array}{l}\text { Imbiriba et } \\
\text { al., (2006) } \\
{[43]}\end{array}$ & $\begin{array}{l}\mathrm{n}=12 \text { (Participants aged } \\
26 \text { years old and } \\
\text { had some type of } \\
\text { blindness) }\end{array}$ \\
$\begin{array}{l}\text { Rodrigues } \\
\text { et al., (2010) }\end{array}$ & $\begin{array}{l}\mathrm{n}=18 \text { (8 males and } 10 \\
\text { [41] }\end{array}$ \\
& $\begin{array}{l}\text { females healthy } \\
\text { with aged } 19 \text { to } \\
33 \text { years old) }\end{array}$
\end{tabular}

Grangeon, $\quad n=20$ (healthy males

Guillot

\& Collet,

(2011)

[44]

Heurley et

al., (2013)

$\mathrm{n}=20$ (healthy students with aged 20 to [46] 24 years old)

\begin{tabular}{l|l} 
Kawasaki & $\mathrm{n}=16$ (7 males and 9 \\
\& Higuchi, & females healthy \\
(2013) $[47]$ & $\begin{array}{l}\text { with aged } 22 \text { to } \\
25 \text { years old })\end{array}$
\end{tabular}

Boulton

\& Mitra, (2013) [45] $\mathrm{n}=48(23$ males and 25 female healthy with aged 18 to 21 years old)

Lemos et al., $\mathrm{n}=23$ (11 males and 12 (2014) [48] females healthy with aged 20 to 38 years old)

Lemos,

Rodrigues

\& Vargas,

(2014) [49]

\author{
$\mathrm{n}=12$ (5 females and \\ 7 males healthy \\ with aged 20 to \\ 33 years old)
}

Similar protocol I used by Rodrigues et al. (2003), though the VMI tasks were not accomplished, due to the patient's blindness

\section{Tasks:}

a) to execute rising on tiptoes;

b) to perform $\mathrm{VMI}$ and $\mathrm{KMI}$ of the same movement and

c) to imagine themselves singing a song (mental control)

The participants executed and imagery three tasks with their eyes closed:

1) to remain standing;

2) to counter- movement jump and 3)finger-to-thumb opposition

The participants had to read short sentences while execute / imagery a situation stable and instable (unipodal stance)

\section{The participants has that} performed mental rotation of a foot (experiment 1) view the foot stimuli (experiment 2) on unipodal and bipodal stance

The participants imagined reaching movements with the feet closed or semi-tandem Romberg stance

The participants imagined three movements using the KMI: (1) rising on tiptoes; functional reach (2) forward and (3) lateral direction. After each task, the subjects reported the level of imagery vividness and were grouped into a high and low group

Tasks: to perform VMI (1) and $\mathrm{KMI}(2)$ rising on tiptoes and (3) imagine singing a song (control task)
Force platform $(50 \mathrm{~Hz})$ and EMGS lateral gastrocnemius

Force platform $(50 \mathrm{~Hz})$ and EMGS lateral gastrocnemius
Force platform $(500 \mathrm{~Hz})$

Force platform
$(100 \mathrm{~Hz})$

The mental simulation task, being absent for resting, counting and executing. The $\mathrm{KMI}$ is strongly associates with somatic and autonomic changes

A significant increase in the displacement and mean velocity of COP in the AP direction in trembling component during the task of KMI, when compared with the tasks VMI and control

\section{A greater variability of body sway of the CoP in the AP and $\mathrm{ML}$ directions during $\mathrm{KMI}$ of opposition and jump tasks, when compared with the VMI}

Force platform $(50 \mathrm{~Hz})$

Force platform $(60 \mathrm{~Hz})$

Force platform $(5 \mathrm{OHz})$ and EMGS of the muscles lateral gastrocnemius and deltoid (medial and anterior)

The result showed that a instable situation decrease the velocity of CoP, when compared with stable situation

The postural velocity of sway for unipodal standing, but not for bipedal standing, were decreased immediately after the foot stimuli, suggesting a immediate postural stability

The result showed reduction in head/trunk sway during motor imagery arm movement in relation to quiet standing

The high group present changes in CoG variability in the AP direction during $\mathrm{KMI}$ of rising on tiptoes. However, the CoG variability in the $\mathrm{ML}$ direction was higher during $\mathrm{KMI}$ of rising on tiptoes and lateral reaching

Force platform $(50 \mathrm{~Hz})$ and EMGS of the muscles lateral gastrocnemius
The KMI promotes a major CoP displacement than VMI and control imagery, with stronger EMGS-CoP temporal association during $\mathrm{KMI}$, suggesting an effect on muscle activity and postural sway

\footnotetext{
Legend: $\mathrm{s=seconds;} \mathrm{Ml}=$ motor imagery; $\mathrm{KMl}=$ kinesthetic motor imagery; $\mathrm{VMI}=$ visual motor imagery; $\mathrm{AP}=$ Anteroposterior ( $\mathrm{Y}$-axis); $\mathrm{ML}=$ Mediolateral $(\mathrm{X}$-axis); $\mathrm{COP}=$ center of pressure; $\mathrm{CoG}=$ center of gravity; EMGS = surface electromyography.
} 


\section{Similarities between of movement execution and motor imagery and its repercussions on postural control}

Different factors may determine the ability of an individual mentally simulate different movements, such as age [56-57], gender [58], the difficulty of the task [59] and fitness level (skill/motor experience) that the participant presents to the designated task [13].

Some properties observed during the ME are also present during the $\mathrm{Ml}$, as their temporal regulation and its biomechanical aspects $[1,3,8$, 60-62], suggesting that there are similarities in the mental states during the execution and imagination of the same task [1, 62-63]. With advances in neuroimaging techniques, this proposal was confirmed, demonstrating the existence of overlap between the neural circuits during the execution and imagination of the same task [64-65]. The circuitry involved in both the execution and the simulation of a task include: supplementary motor area; primary motor cortex; parietal cortex; basal ganglia and cerebellum $[5,64-70]$. Therefore, the motor system is not only involved in the production of voluntary movement, but also in their representational aspects which are accessed during the $\mathrm{Ml}[1,8,63]$.

In the context of postural control, the voluntary movement is accompanied and preceded by anticipatory postural phenomenon [71-72], because postural control is inserted in the context of the movement [73-76]. In studying physiological movement, several researchers showed that the deep muscles of the trunk (antigravity) are activated 50 milliseconds (ms) before the muscle agonist of the movement, both in the lower limb [73-74] as in the upper limb [75]. The evidences indicate that there's a motor recruiting order, in which the deeper muscles of the trunk (antigravity) work in anticipation to the movement from the limbs, in response to the loads imposed by them, to maintain the pos- tural adjustment and the trunk stability during the ME [73-76]. In this context, it could be expected that the $\mathrm{Ml}$ as a physiological movement (different tasks) would recreate the same effect under the control of the postural balance.

Studies suggest that kinesthetic Ml has a network specific sensorimotor that facilitates the corticospinal modulation with more range than the visual MI $[2,65]$. There are speculations that the visual MI occurs through a distinct, related network of mirror neurons (parietal-frontal), which when activated by the observation of an action, allows the meaning of the action automatically, transforming the image stored in the memory in a mental observation of action (third person) [4]. Thus, both the visual strategy of $\mathrm{Ml}$ as kinesthetic $\mathrm{Ml}$ has a distinct mental construction $[2,65]$ and therefore it could be expected that their repercussions on the postural control also behave distinctly, as will be detailed the follow.

\section{Effect of kinesthetic motor imagery on postural control}

Modulations on postural control can be induced by MI. Imbiriba et al (2006) [43] evaluated blind subject having etiological differences. This result suggests that the primary motor representation of the individual who has impaired vision depends on the proprioceptive kinesthetic information [43]. The majority of the results in the present study (see table 3) show that the kinesthetic MI in different type of tasks promotes major changes in postural sway [41-43, 44] and/or EMGS activity [49] when compared with the visual modality. A recent study has shown that kinesthetic $\mathrm{Ml}$ can modulate the postural control. However, this influence occurs only in participants with high levels of vividness of the imagined movement [48], which has been correlated with increased excitability of the motor cortex [77] and changes in spinal-reflex [78] during the MI. Furthermore, the use of $\mathrm{Ml}$ as a mental practice 
(daily training) in clinical rehearsal (see table 2) can improve the balance postural in one leg [26, 46-47] or two leg support [27-28], decrease the oscillation in the AP direction, due to the reduction on the reaction time of the postural control [28].

Some these evidences, together, indicate that kinesthetic $\mathrm{Ml}$ can modulate the postural control depending on the imagined direction of motion. The task of kinesthetic $\mathrm{MI}$ of jump can increase the variability of sway in CoP in the vertical direction (Zaxis) (for review see reference [44]). Tasks kinesthetic $\mathrm{MI}$ of rising on tiptoes can increase the sway in CoP in anteroposterior direction (Y-axis) [41-42, 48]. The task of the functional reach in the lateral direction (lateral reach) shows an increase in the CoG variability in the mediolateral direction (X-axis) [48]. These studies suggest that the postural response during the $\mathrm{Ml}$ presents similarities with the task in each direction ( $Y, X$ and $Z$-axis), indicating the existence of specificity directional of the imagined movement (task-dependent).

Several neural mechanisms are responsible for preparation and programming of the movement, with minimal or none efferent motor activity [1]. Therefore, the $\mathrm{Ml}$ activates not only the motor command (frontal cortex), but also activates the feedback kinesthetic representation (parietal cortex), from sensorial inputs (proprioceptive and exteroceptive) connecting anatomically to the primary motor cortex (cM1) by $U$ fibers (for review see reference [4]). The kinesthetic MI specifically extracts a subconscious activity of the muscles of the mental representation, requiring a proprioceptive ability of perception of the imagined movement (kinesthetic memory) [79]. This ability, integrates proprioceptive information from muscles, tendons and joints in the body position and imagined movement [44], activating specifically somatomotor areas $[2,65]$, and it can modulate the muscle activity associated with changes in CoP [49].

\section{Motor inhibition during the mental simulation of tasks}

A recent review study emphasized three possibilities to inhibit the motor command during the MI: (1) parietal cortex (motor inhibition during the mental representation construction process; (2) frontal cortex (suppressive influences by the cortex in areas designated to formulate the motor command and (3) inhibition influences by the cerebellum and spinal cord. Particularly when a program of movement is not well adapted and changes are required in one or more parameters of directions or even in the range of motion, the full inhibition of the movement is not necessary, but only to adaptation the program to the individual. This flexibility on the mechanism of central inhibition may result in the interaction between the inferior frontal gyrus with the basal ganglia, responsible for programing a motor planning, which could be inhibit (for review see reference [40]).

Depending on the orientation of the movement, a systematic sequence of neuronal activation occurs before the movement begins. EEG registers show that a negative increase of the potential (between 1 and 2 seconds) happens before the $M E$, reflecting in a preparation of the motor process (pre-motor potential) [80]. The negative premotor potential happens fast $(500 \mathrm{~ms})$ before the movement begins and reflects the depolarization of the dendrite network, indicating a preparatory generation of the underlying state of the cortical sensorimotor layer [81]. Studies using functional magnetic resonance imaging (fMRI) suggest that the pre-motor process may be linked to the supplementary motor area (SMA) and the reticular formation nuclei on brainstem [82], probably composing the corticospinal tract that activates the alpha motor neuron of anti-gravitational muscles (stabilizer) [35]. Studies on movement simulation show the connectivity between SMA and CM1 suggesting that SMA inhibits CM1 activity during MI spelling 
gamma-Aminobutyric Acid (GABA) liberation indicating an important feedback circuit of primary motor cortex (CM1) with SMA at the preparation and $\mathrm{ME}$, as well as in $\mathrm{MI}[4,82-83]$.

In this context, studies have shown the participation of both CM1 and SMA not only on simulation, but also on ME, as it seems that the neurons do not codify only the $\mathrm{ME}$, but they are also related to the movement complexity and its learning [77, 82, 84]. Furthermore, MI and ME have showed an effective similarity of corticospinal and intracortical excitability [85]. It seems that a facilitation on corticospinal excitability occurs (SMA) during kinesthetic $\mathrm{Ml}$ associated to the intracortical inhibition (cM1, cerebellum, brainstem and spinal cord) of pre-synaptic fiber of alpha motor neuron (type la), by GABA liberation, leading to volitional muscle relaxation, preventing $\operatorname{ME}[83,86]$. However, this mechanism is still unknown, and lots of hypothesis have emerged about the nearest anatomic areas (SMA and CM1) [82], suggesting that the inhibition of CM1 (pyramidal tracts) during the MI happens on the motor planning stages $[40,87]$, leading to changes in postural control (functional reach test), regardless of age [88].

Another question, in the same context, is that unconscious muscle activity seems to be specific to the type of muscle contraction (concentric or eccentric) during an Ml task [89]. Data shows that there's incomplete inhibition of motor command specifically during kinesthetic Ml tasks $[19,83,90]$, which seems to evoke motor representations involved in balance control, through SMA and CM1 activities modifications [85]. Recently it has been speculated that there may be an integration between slow muscle activity (stabilizer) and fast (mobilizing) during MI [44], just as there is on ME [73-76]. Based on this discussion, it can be suggested that using the kinesthetic $\mathrm{Ml}$ strategy of imagining a task, a cM1 block happens (corticospinal tract) through SMA inhibition activity, which activates the reticuloespinal tract (by SMA activity), promoting changes on anticipatory postural displacement to the imagined movement, which is inhibited or shows minimum activity (feedforward of imagined movement).

\section{Record of the electromyographic signal during tasks of kinesthetic motor imagery involving changes on postural control}

The electromyography (EMGS) includes examining electrical potentials (membrane potential) and consists in the noninvasive assessment of the muscle activity [91]. The EMGS activity during the MI has been widely discussed [92]. Several studies show changes in EMGS during the $\mathrm{MI}$ in different tasks, and this difference was considered a small activity when compared to the amplitude of the signal collected during execution of the movement [89, 93-94]. However, other studies have not observed any change in EMGS during the MI [95-97].

Traditionally, experiments in $\mathrm{Ml}$ and postural control with records from EMGS have used surface electrodes. The antigravity muscles are rich in spindles [98] and kinesthetic MI can induce an increase in the excitability of these spindles [99] and may thus facilitate the antigravity postural adjustment (change in CoP) during mental rehearsal of a task $[41-42,44,48]$. A recent study has shown that kinesthetic $\mathrm{Ml}$ can promote a major CoP displacement with stronger EMGS-CoP temporal association (lateral gastrocnemius) [49]. However, especiaIly small muscle activities or deeper muscles activities (antigravity or stabilizers) during the kinesthetic $\mathrm{Ml}$ can not be registered by EMGS. Because of that, the methods used in EMGS have shown flaws in its reproducibility and reliability, as well as lack of precision in some experimental designs, making them insufficient to validate the interpretation of a data (for review see reference [4]).

The skeletal-muscles have several physiological characteristics and are activated in different frequencies, such as the slow-twitch fibers (type I) activated in low frequencies $(5$ to $20 \mathrm{~Hz}$ ) and fasttwitch fibers (type II) activated in higher frequen- 
cies $(30$ to $100 \mathrm{~Hz})$ (for review see reference [100]). The intensity of mental effort could create different effects in both fast and slow muscle fibers, because its EMGS records must respect the respective physiological frequency range. So it could be necessary to take notes of the records on muscle activation (surface and deep muscles) and its absence/presence during $\mathrm{Ml}$ can be essential to control futures experimental rehearsals involving $\mathrm{Ml}$ and postural control.

\section{Final Considerations}

According to the analyzed literature, the kinesthetic MI has shown more influence over the postural control comparing to the visual modality. However, this influence occurs only in participants with high levels of vividness of the imagined movement. The number of studies at the present moment is limited and the results should be interpreted cautiously, because there may be methodological failures that could occult registers of postural activities during the MI. Thus, more studies need to be performed to answer these and other questions in order to improve techniques for rehabilitation in orthopedic and/or neurological disorders of the postural control.

\section{Competing interests}

The authors declare that they have no competing interests.

\section{Acknowledgments}

OA-C is supported by CONACYT-BMBF 2013 (Grant 208132).

\section{Authors' contribution}

NSS and ACGM participated in the acquisition of data. All authors participated in the revision of the manuscript. DM, VHBH, MO, BV, PR, ST and OAC guided the design and organization of the study. NSS, ACGM and KSC drafted the manuscript. All authors read and gave final approval for the version submitted for publication.

\section{References}

1. Jeannerod M. The representing brain: neural correlates of motor intention and imagery. Behav Brain Sci 1994, 17:187-202.

2. Sirigu A, Duhamel JR. Motor and visual imagery as two complementary and neurally dissociable mental processes. J Cogn Neurosci 2001, 13(7):910-9.

3. Jeannerod M. Mental imagery in the motor context. Neuropsychol 1995, 33(11):1419-32.

4. Guillot A, Collet C: The neurophysiological foundations of mental and motor imagery. New York: Oxford university press, 2010.

5. Jeannerod M. Neural simulation of action: a unifying mechanism for motor cognition. Neuroimage 2001, 14:103-9.

6. Jausovec $\mathrm{N}$, Jausovec $\mathrm{K}$. EEG activity during the performance of complex mental problems. Intl J Psychophysiol 2000, 30:73-88.

7. Decety J, Jeannerod M, Germain M, Pastene J. Vegetative response during imagined movement is proportional to mental effort. Behav Brain Res 1991, 42(1):1-5.

8. Decety, J. Do imagined and executed actions share the same neural substrate? Cogn Brain Res 1996a, 3(2):87-93.

9. Decety J, Jeannerod M, Durozard D, Baverel G. Central activation of autonomic effectors during mental simulation of motor actions in man. J Physiol 1993, 461:549-63.

10. Rienzo F, Hoyek N, Collet C, Guillot A. Physiological changes in response to apnea impact the timing of motor representations: A preliminary study. Behav Brain Funct 2014, 10(1):1-15.

11. Wang $Y$, Morgan WP. The effect of imagery perspectives on the psychophysiological responses to imagined exercise. Behav Brain Res 1992, 52:167-74

12. Wuyam B, Moosavi SH, Decety J, Adams L, Lansing RW, Guz A. Imagination of dynamic exercise produced ventilatory responses which were more apparent in competitive sportsmen. J Physiol 1995, 482:713-24.

13. Feltz DL, Landers DM. The effect of mental practice on motor skill learning and performance. A meta-analysis. J Sport Psychol 1983, 5:25-57.

14. Allami N, Paulignan $Y$, Brovelli A, Boussaoud D. Visuo-motor learning with combination of different rates of motor imagery and physical practice. Exp Brain Res 2008, 184(1):105-13.

15. Saimpont A, Malouin F, Tousignant B, Jackson PL. Motor imagery and aging. J Mot Behav 2013, 45(1):21-28. 
16. Malouin F, Richards $C L$, Durand $A$, Descent $M$, Poiré $D$, Frémont $P$, Doyon J. Effects of practice, visual loss, limb amputation, and disuse on motor imagery vividness. J Neurol Neurophysiol 2009, 23(5):449-63.

17. Dickstein R, Dunsky A, Marcovitz E. Motor imagery for gait rehabilitation in post-stroke hemiparesis. Phys Ther 2004, 84:1167-77.

18. Bakker M, De Lange FP, Helmich RC, Shieringa R, Bleom BR. Cerebral correlates of motor imagery of normal and precision gait. Neurolmage 2008a, 41, 998-1010.

19. Bakker M, Overeem S, Snijders AH, Borm G, Van Elswijk G, Toni I, Bloem BR. Motor imagery of foot dorsiflexion and gait: Effects on orticospinal excitability. Clin Neurophysiol 2008b, 119:251927.

20. Sacco K, Cauda F, Cerliani L, Mate D, Duca S, Geminiani GC. Motor imagery of walking following training in locomotor attention. The effect of 'the tango lesson'. Neuroimage 2006, 32(3):1441-49.

21. Abbas AL, Lucas MF, Teixeira S, Paes F, Velasques B, Ribeiro P, Nardi $A E$, Machado S: Motor imagery and stroke neurorehabilitation: an overview of basic concepts and therapeutic effects. Am J Neurosci 2011, 2(2):59-64.

22. Bastos AF, Carrapatoso BC, Orsini MA, Leite A. Functional recovery of upper limb post-stroke: mental practice with motor and non-motor imagery. Am Med J 2012, 3(1):50-55.

23. letswaart $M$, Johnston $M$, Dijkerman $H C$, Joice $S$, Scott $C L$, MacWalter RS, Hamilton SJC. Mental practice with motor imagery in stroke recovery: randomized controlled trial of efficacy. Brain J neurol 2011, 134:1373-86.

24. Schuster C, Butler J, Andrews B, Kischka U, Ettlin T. Comparison of embedded and added motor imagery training in patients after stroke: results of a randomised controlled pilot trial. Trials J 2012, 13(11):11-19.

25. Kasahara T, Terasaki K, Ogawa Y, Ushiba J, Aramaki $H$, Masakado $Y$. The correlation between motor impairments and event-related desynchronization during motor imagery in ALS patients. BMC neurosc 2012, 13(1):66

26. Fansler $C L$, Poff $C L$, Shepard KF. Effects of mental practice on balance in elderly woman. Phys Ther 1985, 65:1332-38.

27. Choi JH, Choi YW, Nam KS, Cho IS, Hwang YT, Kwon YH. Effect of mental training on the balance control ability of healthy subjects. J Phys Ther Sci 2010, 22:51-55.

28. Hamel MF, Lajoie Y. Mental imagery: effects on static balance and attentional demands of the elderly. Aging Clin Exp Res 2005, 17:223-28

29. Horak FB, Nashner LM. Central programming of postural movements: adaptation to altered support-surface configurations. J Neurophysiol 1986, 55(6):1369-81.

30. Horak FB. Clinical measurement of postural control in adults. Phys Ther 1887, 67(12):1881-85.
31. Horak FB. Postural orientation and equilibrium: what do we need to know about neural control of balance to prevent falls? Age and Aging 2006, 35(2):7-11.

32. Günther $M$, Putsche $P$, Leistritz L, Grimmer S. Phase synchronization of the three leg joints in quiet human stance. Gait \& Posture 2011, 33(3):412-17.

33. Fitzpatrick R, Mccloskey DI. Proprioceptive, visual and vestibular thresholds for the perception of sway during standing in humans. J Psychol 1994, 478(1):173-86.

34. Redfern MS, Yardley L, Bronstein AM. Visual influences on balance. J Anx Disor 2001, 15(1-2):81-94.

35. Bricot, Bernard : La reprogrammation posturale globale. France: Sauramps Médical, 2009.

36. Sherrington CS. Flexion-reflex of the limb, crossed extensionreflex, and reflex stepping and standing. J Physiol 1910, 40:28121.

37. Nashner LM. Adapting reflexes controlling the human posture. Exp Brain Res 1976, 26(1):59-72.

38. Jacobs JV, Horak FB. Cortical control of postural responses. J Neural Transm, 2007, 114(10): 1339-48.

39. Mihara, M, Miyai I, Hatakenaka M, Kubota K, Sakoda S. Role of the prefrontal cortex in human balance control. Neuroimage 2008, 43(2):329-36.

40. Guillot A, Rienzo FD, Maclntyre T, Moran A, Collet C. Imaging is not doing but involves specific motor commands: a review of experimental data related to motor inhibition. Front Hum Neurosci 2012, 6:1-22.

41. Rodrigues EC, Lemos $T$, Gouvea B, Volchan E, Imbiriba LA, Vargas $C D$. Kinesthetic motor imagery modulates body sway. Neurosc 2010, 169(2):743-50.

42. Rodrigues EC, Imbiriba LA, Leite GR, Magalhães J, Volchan E, Vargas CD. Mental simulation strategy affects postural control [article in portuguese]. Rev Bras Psiquiatr 2003, 25:33-5. Doi: 10.1590/S1516-44462003000600008.

43. Imbiriba LA, Rodrigues EC, Magalhaes J, Vargas CD. Motor imagery in blind subjects: the influence of the previous visual experience. Neurosci Lett 2006, 400(1-2):181-85.

44. Grangeon M, Guillot A, Collet C. Postural control during visual and kinesthetic motor imagery. Appl Psychophysiol Biofeedback 2011, 36:47-56.

45. Boulton H, Mitra S. Body posture modulates imagined arm movements and responds to them. J neurophysiol 2013, 110(11):2617-26.

46. Heurley LP, Simoneau EM, Leteneur S, Brouillet D. When motor simulation of disequilibrium increases postural stability. Comput Methods Biomech Biomed Engin 2013, 16(sup1):44-45.

47. Kawasaki T, Higuchi T. Immediate Beneficial Effects of Mental Rotation Using Foot Stimuli on Upright Postural Stability in Healthy Participants. Rehabil Res Pract 2013, 1-7. 
48. Lemos T, Souza NS, Horsczaruk CHR, Nogueira-Campos AA, De Oliveira LS, Vargas CD, Rodrigues EC. Motor imagery modulation of body sway is task-dependent and relies on imagery ability. Front Hum Neurosci 2014, 8(1-9).

49. Lemos $T$, Rodrigues EC, Vargas CD. Motor imagery modulation of postural sway is accompanied by changes in the EMG-COP association. Neurosci Lett 2014. 577:101-05.

50. Dixon-Woods M, Agarwal S, Jones D, Sutton A. Synthesising qualitative and quantitative evidence: a review of possible methods. J Health Sci Res Policy 2005, 10:45-53.

51. Nordahl SH, Aasen T, Eidsvik S. Static stabilometry and repeated testing in a normal population. Origin res 2000, 71(9):889-93.

52. Doyle RJ, Hsiao-Wecksler ET, Ragan BG, Rosengren KS. Generalizability of center of pressure measures of quiet standing. Gait \& Posture 2007, 27:166-71.

53. Doyle RJE, Tim L, Newton RU, Burnett AF. Reability of traditional and fractal dimensional measures of quiet stance center of pressure in young, healthy people. Arch Phys Med Rehabil 2005, 86:2034-40.

54. Pinsault N, Vuillerme V. Test-retest reliability of centre of foot pressure measures to assess postural control during unperturbed stance. Med Eng Phys 2009, 31(2):276-86.

55. Santos BR, Delisle A, Larivière C, Plamondon A, Imbeau D. Reliability of centre of pressure summary measures of postural steadiness in healthy young adults. Gait and posture 2008, 27(3):408-15.

56. Mulder T, Hochstenbach JBH, Van Heuvelen MJG, Den Otter AR. Motor imagery: the relation between age and imagery capacity. Hum Movement Sci 2007, 26(2):203-11.

57. Malouin F, Richards C, Durand A. Normal aging and motor imagery vividness: implications for mental practice training in rehabilitation. Arch Phy Med Rehabil 2010, 91(7):1122-27.

58. Hoyek N, Champely S, Collet C, Fargier P, Guillot A. Age and gender-related differences in the temporal congruence development between motor imagery and motor performance. Learn Individ Differ 2009, 19(4):555-60.

59. Decety J, Lindgren M. Sensation of effort and duration of mentally executed actions. Scand J Psychol 1991, 32(2):97-104.

60. Decety J, Jeannerod M, Prablanc C. The timing of mentally represented actions. Behav Brain Res 1989, 34(1): 35-42.

61. Parsons LM. Temporal and kinematic properties of motor behavior reflected in mentally simulated action. J Exp Psychol 1994, 20(4): 709-30.

62. Decety J, Jeannerod M. Mentally simulated movements in virtual reality: does fitts's law hold in motor imagery? Behav Brain Res 1996, 72(1):127-34

63. Decety, J. The neurophysiological basis of motor imagery. Behav Brain Res 1996b, 77(1):45-52
64. Roth M, Decety J, Raybaudi M, Massarelli R, Delon-Martin C, Segebarth C, Jeannerod, M. Possible involvement of primary motor cortex in mentally simulated movement: A functional magnetic resonance imaging study. NeuroReport 1996, 7(7):1280-4.

65. Ruby P, Decety J. Effect of subjective perspective taking during simulation of action: a PET investigation of agency. Nature Neurosci 2001; 4(5):546-50.

66. Decety J, Perani D, Jeannerod M, Bettinardi V, Tadary B, Woods R, Mazziotta JC, Fazio F. Mapping motor representations with PET. Nature, v. 371, p. 600-02, 1994.

67. Lotze $M$, Montoya $P$, Erb $M$, Hülsmann E, Flor $H$, Klose U, Birbaumer N, Grodd W. Activation of cortical and cerebellar motor areas during executed and imagined hand movements: an fMRI study. J Cogn Neurosci 1999, 11(5):491-501.

68. Gerardin E, Sirigu A, Lehéricy S, Poline JB, Gaymard B, Marsault C, Agid Y, Le Bihan D. Partially overlapping neural networks for real and imagined hand movements. Cereb Cortex 2000, 10(11):1093-104.

69. Guillot A, Collet C, Nguyen VA, Malouin F, Richards C, Doyon J. Functional neuroanatomical networks associated with expertise in motor imagery. Neurolmage 2008, 41(4):1471-83.

70. Zapparoli L, Invernizzi P, Gandola M, Verardi M, Berlingeri M, Sberna M, Paulesu E. Mental images across the adult lifespan: a behavioral and fMRI investigation of motor execution and motor imagery. Exp Brain Res 2013, 224(4):519-40.

71. Massion J. Movement, posture and equilibrium: Interaction and coordination. Progress in Neurobiology 1992, 38(1):35-56.

72. Massion J. Postural control systems in developmental perspective. Neurosci Biobehav Rev 1998, 22(4):465-72.

73. Hodges PW, Richardson CA. Contraction of the abdominal muscles associated with movement of the lower limb. Phys Ther 1997, 77(2):132-44.

74. Hodges PW. Changes in motor planning of feedforward postural responses of the trunk muscles in low back pain. Exp Brain Res 2001, 141:261-66.

75. Falla D, Jull G, Hodges PW. Feedforward activity of the cervical flexor muscles during voluntary arm movements is delayed in chronic neck pain. Exp Brain Res 2004, 157:43-8. Tsao H, Hodges PW. Immediate changes in feedforward postural adjustments following voluntary motor training. Exp Brain Res 2007, 181(4):537-46.

76. Lebon F, Byblow WD, Collet C, Guillot A, Stinear CM. The modulation of motor cortex excitability during motor imagery depends on imagery quality. Eur J Neurosci 2012b, 35(2):32331.

77. Aoyama $T$ \& Kaneko $F$. The effect of motor imagery on gain modulation of the spinal reflex. Brain res 2011, 1372:41-8.

78. Lacourse MG, Orr EL, Cramer SC, Cohen MJ. Brain activation during execution and motor imagery of novel and skilled sequential hand movements. Neuroimage 2005, 27(3):505-19. 
79. Walter W, Cooper R, Aldridge VJ, McCallum WC, Winter AL. Contingent negative variation: an electric sign of sensori-motor association and expectancy in the human brain. Nature 1964, 203:380-84

80. Boschert J, Hink RF, Deecke L. Finger movement versus toe movement-related potentials: further evidence for supplementary motor area (SMA) participation prior to voluntary action. Exp Brain Res 1983, 52(1) 73-80.

81. Kasess $\mathrm{CH}$, Windischberger $C$, Cunnington $\mathrm{R}$, Lanzenberger $R$, Peza-was L, Moser E. The suppressive influence of SMA on CM1 in motor imagery revealed by $\mathrm{fMRI}$ and dynamic causal modeling. Neuroimage 2008, 40(2):828-837.

82. Stinear CM, Byblow WD. Role of intracortical inhibition in selective hand muscle activation. J. Neurophysiol 2003, 89(4):2014-20.

83. Lebon F, Lotze M, Stinear CM, Byblow WD. Task-dependent interaction between parietal and contralateral primary motor cortex during explicit versus implicit motor imagery. Plos one 2012a, 7(5):e37850.

84. Guillot A, Collet C, Nguyen VA, Malouin F, Richards C, Doyon J. Brain activity during visual versus kinesthetic imagery: an fMRI study. Hum Brain Mapp 2009, 30:2157-172.

85. Fourkas AD, Avenanti A, Urgesi C, Aglioti SM. Corticospinal facilitation during first and third person imagery. Exp Brain Res 2006, 168(1-2):143-51.

86. Vigneswaran G, Philipp R, Lemon RN, Kraskov A. CM1Corticospinal mirror neurons and their role in movement suppression during action observation. Report 2013, 23(3):1-6.

87. Gabbard C, Cordova A. Association between imagined and actual functional reach (FR): A comparison of young and older adults. Arch Gerontol 2013, 56:487-91.

88. Guillot A, Lebon F, Rouffet D, Champely S, Doyon J, Collet C. Muscular responses during motor imagery as a function of muscle contraction types. Int J Psychophysiol 2007, 66:18-27.

89. Stinear CM, Byblow WD, Steyvers $M$, Levin O, Swinnen SP. Kinesthetic, but not visual, motor imagery modulates corticomotor excitability. Exp Brain Res 2005, 168(1-2):157-64.

90. Hermens HJ, Freriks B, Disselhorst-Klug C, Rau G. Development of recommendations for SEMG sensors and sensor placement procedures. J Electromyogr Kinesiol 2000, 10(5), 361-374.

91. Jeannerod M, Decety J. Mental motor imagery: a window into the representational stages of action. Curr Opin Neurobiol 1995, 5(6):727-32.

92. Dickstein R, Gazit-Grunwald M, Plax M, Dunsky A, Marcovitz E. EMG activity in selected target muscles during imagery rising on tiptoes in healthy adults and post strokes hemiparetic patients. J Mot Behav 2005, 37(6):475-83.

93. Lebon F, Rouffet D, Collet C, Guillot A. Modulation of EMG power spectrum frequency during motor imagery. Neurosci Lett 2008, 435(3):181-85
94. Yue G, Cole KJ. Strength increases from the motor program: comparison of training with maximal voluntary and imagined muscle contractions. J Neurophysiol 1992, 67(5):1114-23.

95. Lafleur MF, Jackson PL, Malouin F, Richards CL, Evans $A C$, Doyon J. Motor learning produces parallel dynamic functional changes during the execution and imagination of sequential foot movements. Neuroimage 2002, 16(1):142-57.

96. Gentili R, Papaxanthis C, Pozzo T. Improvement and generalization of arm motor performance through motor imagery practice. Neurosci 2006, 137(3):761-72.

97. Nitz AJ, Peck D. Comparison of muscle spindle concentrations in large and small human epaxial muscles acting in parallel combinations. Am Surg 1986, 52(5):273 77.

98. Gandevia SC, Wilson LR, Inglis JT, Burke D. Mental rehearsal of motor tasks recruits alpha-motoneurones but fails to recruit human fusimotor neurones selectively. J physiol 1997, 505(Pt 1), 259-66.

99. Norris, CM. Spinal stabilization: 4. Muscle imbalance and the low back. Physiother 1995, 81(3):127-38.

\section{Comment on this article:}

\section{8 in $8+\mathbf{S} P$}

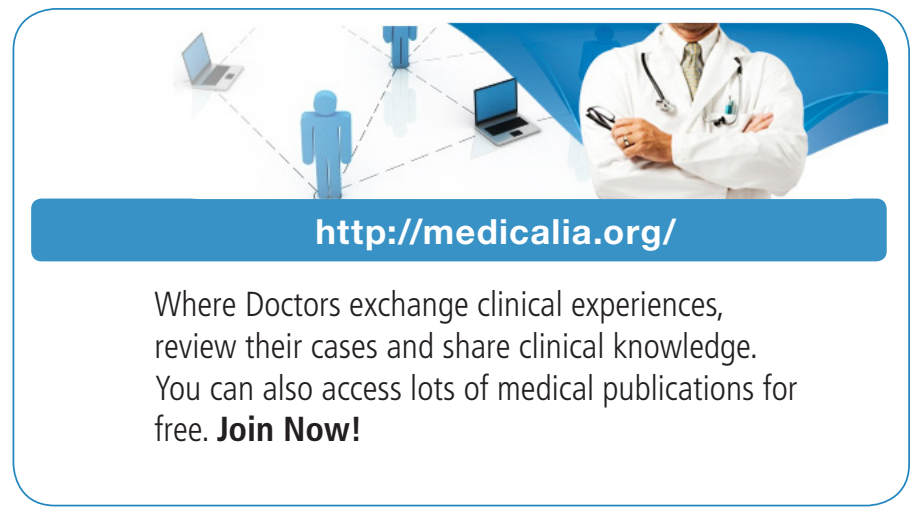

\section{Publish with iMedPub}

\section{http://www.imed.pub}

International Archives of Medicine is an open access journal publishing articles encompassing all aspects of medical science and clinical practice. IAM is considered a megajournal with independent sections on all areas of medicine. IAM is a really international journal with authors and board members from all around the world. The journal is widely indexed and classified Q1 in category Medicine. 